\title{
Punishing effects of long delays of reinforcement with shock-escape behavior*
}

\author{
L. J. HAMMOND and JOSEPH V. LAMBERT \\ Temple University, Philadelphia, Pa. 19122
}

Rats receiving long delays of reinforcement in a shock-escape runway (30 or $45 \mathrm{sec}$ of goalbox confinement before relief) ran quite slowly on later, as compared to earlier, acquisition trials. In this sense, long delays of relief appeared to punish running. A psychophysical interpretation was given. In the case of escape behavior, longer delays of reinforcement may result in definitely discernable increments in shock (drive) duration, whereas in the case of rewarded behavior, a minute or more of hunger is probably not above the difference limen based on a standard of $24 \mathrm{~h}$ of hunger.

One curious aspect of the study of discrete-trial escape behavior concerns the application of nonreinforcement at the end of a trial. Once the event of nonreinforcement is over, the $\mathrm{E}$ must decide either to maintain the drive (aversive) condition or to deliver complete reinforcement (relief from the aversive condition) during the intertrial interval (ITI). The usual choice is to deliver complete reinforcement during the ITI. Indeed, it is the only choice where animals are handled between trials.

In this context it would be desirable to know how long one must wait before ITI events no longer influence the designated instrumental response. The present experiment was designed to provide an answer to this pragmatic question for shock-escape behavior of rats in the runway. Theoretically this is a question about the empirical nature of the delay-of-reinforcement gradient.

Drawing from the many studies of such gradients for rewarded behavior, it would be expected that, where secondary reinforcement effects are minimal, there should be no reinforcement effect after the reinforcer is delayed for $5-10 \mathrm{sec}$ (e.g., Bolles, 1967, pp. 336-342). Thus, as parametric studies of delay of reinforcement include groups receiving longer and longer delays, a point should be reached where extended-delay groups produce virtually overlapping and relatively flat curves during the acquisition period. Of course, this assumes that the only factor influencing instrumental behavior in the extended-delay case is the process of positive reinforcement (either reward or relief).

*This research was supported by NIMH Grant MH-16540-02 to the senior author. We wish to thank William Love III and Joel Ways for skillful aid in collecting this data, and Professor Philip Bersh for helpful criticism of the concepts presented here. Reprints may be obtained from Lynn J. Hammond, Department of Psychology, Temple University. Philadelphia, Pa. 19122.
For escape behavior, several studies have indicated that delay of reinforcement acts in a manner similar to that for rewarded behavior. In the study of cold-water escape in rats, Woods \& Feldman (1967) found greatly attenuated learning after $3 \mathrm{sec}$ of delay of relief and no learning after a 10-sec delay. Fowler \& Trapold (1962) conducted an extensive parametric study of delay of relief for rats escaping from shock in the runway. Learning effects were systematically attenuated for increasing delays of $1,2,4,8$, and $16 \mathrm{sec}$. Although most of the acquisition effects occurring with the 0 -sec delay group were not present in the 16-sec delay group, the mean acquisition curve for this last group still showed some increase from the first to the latter trial blocks. Thus, it was not known whether or not reinforcement was occurring at $16 \mathrm{sec}$ of delay for shock escape in the runway.

The present experiment selected values of delay of reinforcement $(0,15,30$, and $45 \mathrm{sec})$ for shock-escape behavior of rats in a runway which extended the maximum value used in the Fowler \& Trapold (1962) study and which would have hopefully resulted in a lack of acquisition for the extended-delay groups.

\section{SUBJECTS}

Thirty-two male rats of the Sprague-Dawley strain, weighing 150-200 g (Camm Research Institute, N.J.), were assigned randomly to four equal groups: a 0-, 15-, 30-, or 45-sec delay group. APPARATUS

A 10-ft-long straight alley, 2-5/8-in.-wide inside dimension, served as the apparatus. It consisted of a $1-\mathrm{ft}$ startbox, an $8 \cdot \mathrm{ft}$ runway, and a $1 \mathrm{ft}$ goalbox. Guillotine doors separated these three compartments. The walls and floor of each compartment were composed of two L-shaped metal runners, which formed the shocking surface. A 5/8-in. gap running lengthwise down the floor separated the L-shaped metal runners. Photocells were placed 3 in. into the runway from the startbox door and 3 in. into the goalbox from the runway door. Running times for this 8 - $\mathrm{ft}$ distance were recorded on a standard electric clock. A constant-current source producing $.85 \mathrm{~mA}$ across the runners supplied the aversive footshock. This apparatus with this particular type of shock source has been shown to produce very efficient escape behavior (Lambert \& Hammond, 1970). A more detailed description of this apparatus is contained in that report.

\section{PROCEDURE}

The rats were run two at a time by four separate Es. Type of delay condition and the particular E, as well as the order of running, were counterbalanced. Each rat was placed in the startbox while shock was off, and the exit door was raised when the rat was oriented toward the door. The shock was turned on throughout the entire apparatus at the moment the gate was raised. Upon entry into the goalbox, that entry door was lowered and shock was turned off after $0,15,30$, or $45 \mathrm{sec}$, as measured on a stopwatch, depending upon the treatment of the particular rat. Each rat received 14 trials exactly as above and was placed in a holding cage during each intertrial interval of approximately $2 \mathrm{~min}$. If a rat failed to enter the goalbox within $60 \mathrm{sec}$, shock was turned off and the rat was removed to its holding cage to await its next trial.

\section{DATA ANALYSIS}

Running times for the 8-ft runway distance between the photocells were not converted to speed but were averaged in two-trial blocks for each animal. Also, in order to examine the degree of acquisition, an acquisition-difference score was obtained for each rat by subtracting the mean time of the last two trials from the time on the first trial.

\section{RESULTS}

Mean running times in seconds for each of the delay groups during the course of acquisition are plotted in Fig. 1. The 0-sec

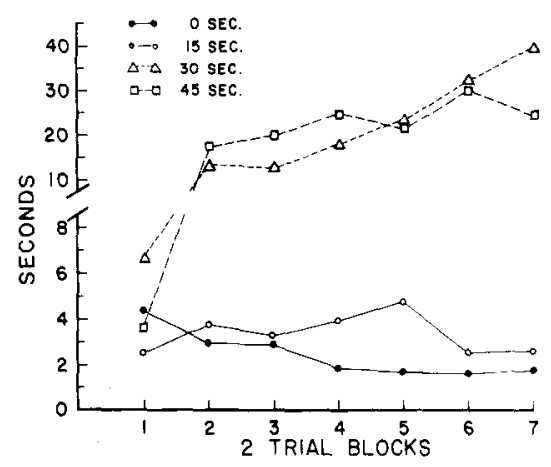

Fig. 1. Mean time to run the 8-ft alley for the four delay groups plotted across two-trial blocks of acquisition. Note the change in scale that takes place between 8 and $10 \mathrm{sec}$ on the ordinate. 
group shows a shallow acquisition curve, while the 15-sec group does not appear to change its running time during the 14-trial period. But both the $30-\mathrm{sec}$ and the $40-\mathrm{sec}$ delay groups are qualitatively different from the 15-sec group. Both of these groups show a dramatic decrease in running time (note the change in scale between 8 and $10 \mathrm{sec}$ on the ordinate of the figure).

Nonparametric statistics computed with the acquisition-difference scores confirm these descriptive conclusions. A Kurskal-Wallis one-way analysis of variance revealed that the groups differed from each other $(\mathrm{H}=-99, \mathrm{df}=3, \mathrm{p}<.001)$. Multiple Mann-Whitney Us calculated on all possible combinations of four groups revealed that the $0-\mathrm{sec}$ group differed from the $15-\mathrm{sec}$ group $(\mathrm{p}=.032)$, from the $30 \mathrm{sec}$ group $(\mathrm{p}<.001)$, and from the $45 . \mathrm{sec}$ group $(\mathrm{p}<.001)$; and the $15-\mathrm{sec}$ group also differed from the 30-sec group $(p<.002)$ and the 45 -sec group ( $\mathrm{p}<.003$ ); but the 30 and $45-\mathrm{sec}$ groups did not differ from each other.

Of most interest in the present study were statistical evaluations of the direction of change from the first to the latter trials. Wilcoxon matched-pairs signed-ranks tests for each group revealed that the 0 -sec group (mean acquisition-difference score = $-1.07)$ significantly decreased their running times during acquisition $(\mathrm{T}=0$, $\mathrm{N}=8, \mathrm{p}<.01)$. The $15-\mathrm{sec}$ group (mean $=-.47$ ) did not change significantly $(\mathrm{T}=13, \mathrm{~N}=8, \mathrm{p}>.05)$. On the other hand, both the $30-\mathrm{sec}$ group (mean $=+38.39$ ) and the 45 -sec group (mean $=+24.54)$ significantly increased their running times $(T=2, \quad T=1$, respectively, $\mathrm{N}=8, \mathrm{p}<.02$ ). It is this last dramatic increase in running time that strongly suggests that these longer delays were actually punishing.

\section{DISCUSSION}

Given these results, the question of how long one must wait before ITI events no longer reinforce instrumental escape behavior appears to be a naive one, for these results suggest that there are two types of reinforcing processes that can take place in the period following a given instance of the instrumental response: a positively-reinforcing process that is lessened with increasing time from the response and a negatively-reinforcing process that becomes greater with increasing time since the response.

The suggestion that longer delays are punishing is an inference from the data, since this study contains no control condition for comparison (in fact, such a control is difficult to imagine). This inference is based on the fact that this particular shock level has been shown to be a powerful elicitor of running behavior in this apparatus (Lambert \& Hammond, 1970). It seems unlikely that these elicitive properties of the shock would undergo adaptation within six trials if not positively reinforced by shock termination.

If this inference is accepted, then delay-of-relief gradients appear to be quite different from delay-of-reward gradients. Why? One possible interpretation is psychophysical. If a hungry rat is not reinforced at the end of a trial, then the additional period of the drive condition (hunger), which follows the instrumental response before the next trial, is usually a matter of minutes. Adding these few minutes of the drive condition (hunger) to the $24 \mathrm{~h}$ of the drive that preceded is probably imperceptible. On the other hand, the rat in the shock-escape case typically receives a few seconds of shock during a given trial. The addition of 30 or $45 \mathrm{sec}$ of shock in the goalbox is more than likely to be perceived, since it is in the order of a 15- or 20-fold increase in the total amount of shock received. In other words, it may be that the perception of drive duration follows Weber's law. According to this interpretation, as drive duration increased preceding and during a trial, it would require an increasingly greater duration of additional drive condition at the end of a trial (delay of reinforcement) to produce a punishment effect from such delays. In situations where the drive condition is maintained for long periods before the trial, i.e., the appetitive drive case, the typical delay-of-reinforcement period would add a drive-duration increment well below the difference limen for producing motivational effects. Thus, delay-of-reinforcement gradients would be governed only by the effects of nonreinforcement. However, in the cases where the delay period adds drive-duration increments above the difference limen, both a punishment and a nonreinforcement process will operate to produce the gradient of delay of reinforcement.

In summary, we have found that the delay-of-reinforcement variable is quite different for shock escape (relief) than has been the typically described case for rewarded behavior. This is the second instance of a difference between relief and reward that we have recently encountered. In the other instance, we found that the Amselian frustration effect (FE) as measured by running in a tandem or double alley produced a "reversed" FE. Rats slow down after experiencing frustrative nonvelief instead of speeding up, as is the case after frustrative nonreward (Lambert \& Hammond, in press). It seems highly probable that these two instances involving differences between the effects of relief and reward, one for delay of reinforcement and one for frustration effects, are highly related, although we are unable to specify exactly the nature of such a hypothetical relationship at the present time.

\section{REFERENCES}

BOLLES, R. C. Theory of motilation. New York: Harper \& Row, 1967.

loWLER, H., \& TRAPOLD, II. A. Escape performance as a function of delay of reinforcement. Journal of lixperimental Psychology, 1962, 63, 464-467.

LAMBERT, J. V., \& HAMMOND. L. J. leffects of shock source and method of contact upon runway escape behavior. Behavior Research Methods \& Instrumentation. 1970, 2.11-13.

LAMBERT, J. V.. \& HAMMOND, L. J. Effect of frustrative nonrelief upon shockescape behavior in the double runway. Journal of Experimental Psychology, in press.

WOODS, P. J., \& FELDMAN, G. B. Combination of magnitude and delay of reinforcement in instrumental escape conditioning. Journal of Comparative \& Physiological Psychology, $1966.62,149-151$. 